\title{
Labor tax reform, unemployment, and search
}

\author{
Ben J. Heijdra • Jenny E. Ligthart
}

Published online: 9 January 2008

(C) The Author(s) 2008. This article is published with open access at Springerlink.com

\begin{abstract}
A key obstacle to reducing payroll taxes in many industrialized and transition countries is the direct revenue loss to the government that it implies. This paper studies a simple and practical labor tax reform of reducing a payroll tax and increasing a progressive wage tax that keeps the marginal tax wedge unchanged. Such a strategy increases employment, reduces the equilibrium unemployment rate, and increases public revenue as long as workers do not have all the bargaining power in wage negotiations. Moreover, welfare rises if workers' bargaining power is sufficiently large to exceed a critical value determined by the second-best Hosios condition.
\end{abstract}

Keywords Labor tax reform - Equilibrium unemployment - Invariance of incidence proposition $\cdot$ Payroll taxes $\cdot$ Search and matching model

JEL Classification J3 $\cdot$ J680

B.J. Heijdra · J.E. Ligthart (凶)

Department of Economics, University of Groningen, P.O. Box 800, 9700 AV Groningen,

The Netherlands

e-mail: j.ligthart@uvt.nl

B.J. Heijdra

e-mail: b.j.heijdra@rug.nl

B.J. Heijdra

Netspar, Tilburg, The Netherlands

B.J. Heijdra

Institute for Advanced Studies (IHS), Vienna, Austria

J.E. Ligthart

CentER and Department of Economics, Tilburg University, P.O. Box 90153, 5000 LE Tilburg,

The Netherlands 


\section{Introduction}

Labor tax reform continues to be a key item on the policy agenda of many European countries. High labor tax wedges-generally defined as the difference between the gross wage firms are paying and the after-tax wage income of workers-are often seen as one of the culprits of the high equilibrium unemployment rates of these countries. A piecemeal reduction in the marginal tax wedge is, therefore, a common measure found in European tax reform programs aimed at stimulating employment. In particular, policy makers have recommended cuts in payroll taxes to reduce unemployment (e.g., OECD 1994). ${ }^{1}$

Some observers (e.g., Symons and Robertson 1990) argue that the composition of the tax wedge matters for employment and real wages. They argue that shifting the composition of the tax wedge from payroll taxes (i.e., the employer's part of labor taxes) to wage taxes (i.e., the employee's part of labor taxes) could increase employment. ${ }^{2}$ Indeed, in view of governments' revenue needs, several OECD countries have taken this approach in reforming their direct tax system. For example, Hungary cut its employers' social insurance contribution rates by 11 percentage points during 1994-1999, while increasing its effective labor income tax rates from $24 \%$ to $28 \%$. Several other central and eastern European countries-featuring high rates of unemployment and overstretched public finances-still have to decide on their structural reform strategies. A pivotal policy question is whether a shift in the composition of the tax wedge would be of help in alleviating the unemployment and budgetary problems of these countries.

As a matter of general principle, it is well known that in perfectly competitive labor markets the "invariance of tax incidence proposition" holds. ${ }^{3}$ This proposition says that it does not matter to gross wages, net wages, and employment whether (statutory) labor taxes are levied on workers or firms. ${ }^{4}$ It is not immediately evident, however, whether wage taxes and payroll taxes are equivalent in an imperfectly competitive labor market. For example, unions are unlikely to accept a wage reduction to offset an increase in payroll taxes, but may agree to refrain from wage increases if wage taxes are increased. Empirical evidence is mixed and sensitive to the time dimension. Studies employing wage-bargaining models (e.g., Lockwood and Manning 1993; Holm et al. 1994) suggest that payroll and wage taxes have quite differing effects

\footnotetext{
${ }^{1}$ Empirical studies on the employment effects of payroll taxes generally find small negative effects (see Hamermesh 1993). Summers (1989) argues that the effect may even be negligible if workers value the associated benefits (i.e., health care services, unemployment protection, and pension allowances) enough so that they are willing to accept a lower wage in combination with these benefits. In the present paper, payroll taxes are considered to be akin to a tax.

${ }^{2}$ Throughout the paper, we define wage taxes to include all labor taxes levied on employees' wages (including employees' social security contributions), whereas payroll taxes are defined to refer to social security contributions levied on employers.

${ }^{3}$ The invariance of tax incidence proposition is also sometimes called "Dalton's law" (Dalton 1954) or "tax liability side equivalence." See Riedl and Tyran (2005).

${ }^{4}$ This raises the question why, in practice, social security contributions are divided between employers and employees. Musgrave and Musgrave (1987) argue that the legislative intent may have been to share the tax burden equally, although this does not say anything about the economic incidence. Other factors may play a role as well such as liability to tax evasion and tax administration concerns.
} 
on wage formation. Some studies find that a shift from payroll taxes to wage taxes decreases firms' wage costs, but others cannot find a significant effect (see Symons and Robertson 1990). The composition of the tax wedge seems to play more of a role in the short run than in the long run (cf. Leibfritz et al. 1997), reflecting the greater flexibility of production factors in the long run.

The analytical literature offers surprisingly little guidance on what kind of labor tax reform policy makers should employ to reduce equilibrium unemployment without putting the government's revenue position at risk. Only a few formal studies have studied the invariance of tax incidence proposition in a setting of imperfectly competitive labor markets (cf. Koskela and Schöb 1999; Picard and Toulemonde, 2001, 2003). In such a framework, households and firms may have different degrees of bargaining power over wages, and, therefore, differ in their ability to shift labor taxes. Koskela and Schöb (1999) and Picard and Toulemonde (2001) employ "right-tomanage" trade union models ${ }^{5}$ and find that a revenue-neutral substitution of proportional wage taxes for payroll taxes has no effect on employment. However, Koskela and Schöb (1999)—building on the partial equilibrium frameworks of Koskela and Vilmunen (1996) and Pissarides (1998)—show that positive employment effects are obtained if wage taxes are progressive. So far, little attention has been paid to labor tax reform in search-theoretic models of the labor market. ${ }^{6}$ A notable exception is Picard and Toulemonde (2003), who analyze the employment effects of a revenue-neutral labor tax reform when labor taxes are nonlinear. These authors, however, neither focus on the welfare effects of labor tax reform (reflecting the partial equilibrium nature of their analysis) nor endogenize the labor force participation decision.

The aim of the paper is to analyze the allocation and welfare effects of a coordinated reform that reduces payroll taxes and increases progressive wage taxes. Rather than focusing on revenue-neutral tax reforms, as is common in the public economics literature, we consider a strategy of keeping the marginal tax wedge constant. Our approach allows us to focus on the composition of the tax wedge, and thus abstracts from the effects of a change in the level of the tax wedge. Besides being analytically convenient, this strategy is also practical. Compared with a revenue-neutral restructuring-which requires an analysis of complex tax base effects-all that is needed is information on marginal tax rates.

We embed a standard search-theoretic framework along the lines of Pissarides (1990) in a micro-founded macroeconomic model of a small open economy, which features a perfectly competitive goods market. ${ }^{7}$ The search-theoretic component of the model features flows in the labor market from the (endogenous) creation of new jobs and the (exogenous) destruction of existing jobs. It is assumed that job-seeking workers and vacancy-offering firms match in a stochastic fashion. This modeling setup gives rise to a search externality, which is represented by agents' contact probabilities as a function of labor market tightness. Search externalities yield a subop-

\footnotetext{
${ }^{5}$ In this setup, firms bargain with unions over the wage subject to the restriction that employment is on the labor demand curve. See also Heijdra and Van der Ploeg (2002, Chap. 8).

${ }^{6}$ Boone and Bovenberg (2002) employ the search and matching framework to study the optimal design of labor taxes. Issues of tax design are beyond the scope of the present study.

${ }^{7}$ See Rogerson et al. (2005) for a survey of search-theoretic models of the labor market.
} 
timal decentralized market outcome in which vacancies and unemployment coexist. Because of preexisting labor taxes, the market outcome is second best.

We have chosen to employ a micro-founded macroeconomic framework for three reasons. First, it allows us to endogenize labor supply along the extensive margin (i.e., the labor force participation decision). The majority of the search literature, however, assumes exogenous labor supply. ${ }^{8}$ By modeling endogenous labor supply and allowing for preexisting labor taxes, we are able to study tax incidence issues taking into account both the supply and demand side of the labor market. More specifically, we employ a linear tax scheme with an income threshold to study the effects of tax progressivity on employment, unemployment, and full consumption. Second, by explicitly modeling household behavior, we can study the welfare effects of tax reform. So far, studies have not addressed welfare issues in a search and matching context. Indeed, such an analysis would be trivial in the standard framework because of the assumptions of risk-neutral households (i.e., utility is linear in private consumption) and exogenous labor supply. Finally, the small open economy context provides a justification for an exogenously given (and fixed) rate of interest. Many of the smaller European countries face such an external environment. Furthermore, in the absence of interest rate effects, we can characterize the allocation and welfare effects analytically.

Our approach is shown to yield efficiency gains - in terms of a smaller search externality to job-seeking workers, giving rise to higher employment-without jeopardizing public revenue if the wage tax structure is progressive. Indeed, public revenue is shown to rise. Moreover, such a reform yields an increase in welfare if workers have a sufficient amount of bargaining power. If labor supply is exogenous, a sufficient condition to yield a welfare improvement is that workers' bargaining power should be larger than or equal to the first-best optimal value (which follows from the Hosios (1990) condition). The necessary condition for welfare improvement, however, implies a much smaller degree of workers' bargaining power than prescribed by the sufficiency condition. If labor supply is endogenous, more complex conditions are needed.

The paper is organized as follows. Section 2 develops the basic search-theoretic model, which is extended for endogenous labor supply. Section 3 closes the model, derives equilibrium conditions, and presents the graphical framework used in analyzing the reform. Section 4 studies the allocation and revenue effects of the labor tax reform experiment. Section 5 presents the welfare effects. Section 6 concludes.

\section{Search and matching in a small open economy}

This section embeds a standard search-theoretic model of the labor market in a microfounded macroeconomic model, which incorporates endogenous labor supply and various labor tax instruments. The sequencing of agents' decisions is as follows. The

\footnotetext{
${ }^{8}$ Notable exceptions are Pissarides (2000), Heijdra and Ligthart (2002), and Shapiro (2004), who endogenize labor supply along the extensive margin. In contrast to Pissarides (2000), Heijdra and Ligthart's specification of the utility function is very different; it is concave in private consumption and leisure and explicitly features the labor supply elasticity. The contributions of Hansen (1999) and Shi and Wen (1999) consider endogenous labor supply along the intensive margin (i.e., the working hours decision).
} 
government sets tax policy in the first stage. Subsequently, workers and firms search for a suitable match. After parties have been matched, workers and firms bargain over the wage.

\subsection{Firms}

The production side of the economy consists of a large number of risk-neutral firms, each of which is producing a homogeneous good under perfect competition. For convenience, the number of firms is fixed and normalized to unity. The representative firm produces output, $Y$, according to $Y=\alpha L$, where $L$ denotes units of labor time and $\alpha>0$ is a constant productivity index. For simplicity, physical capital is abstracted away. ${ }^{9}$ The firm's labor stock adjusts sluggishly because it has to post vacancies, $V$, and find workers to fill them. New employment is defined as the difference between job creation, $q V$, and job destruction, $s L$ :

$$
\dot{L} \equiv q V-s L, \quad 0<q<1,
$$

where $q$ represents the probability of the firm finding an unemployed worker with whom it concludes a deal (and thus $1 / q$ is the expected duration of a vacancy, see Sect. 2.4) and $s$ is the exogenous job destruction rate. ${ }^{10}$ A dot above a variable denotes a time derivative (e.g., $\dot{L} \equiv \mathrm{d} L(t) / \mathrm{d} t$ ). For convenience, time subscripts have been dropped where no confusion arises.

By normalizing the price of final output to unity, the firm's objective function can be written as:

$$
A_{\mathrm{P}}(t) \equiv \int_{t}^{\infty}\left[Y(z)-\gamma V(z)-w_{P}(z) L(z)\right] \mathrm{e}^{-r(z-t)} \mathrm{d} z, \quad \gamma>0,
$$

where $A_{\mathrm{P}}$ is the value of the firm, $\gamma$ is the (constant) flow cost per vacancy (modeled in terms of output lost $), w_{\mathrm{P}} \equiv w\left(1+\tau_{\mathrm{E}}\right)$ denotes the producer wage, $w$ is the beforetax wage, and $\tau_{\mathrm{E}}$ is an ad valorem payroll tax. The rate of interest, $r$, is exogenously given, reflecting that the domestic economy is small in world capital markets.

The firm is assumed to have perfect foresight. It chooses time paths of employment and vacancies in order to maximize (2) subject to the production function and the employment accumulation constraint (1). Optimal firm behavior is characterized by:

$$
\begin{aligned}
\lambda_{\mathrm{E}}(t) & =\frac{\gamma}{q}=\int_{t}^{\infty}\left[\alpha-w_{\mathrm{P}}(z)\right] \mathrm{e}^{-(r+s)(z-t)} \mathrm{d} z, \\
A_{\mathrm{P}} & =\lambda_{\mathrm{E}} L .
\end{aligned}
$$

The first equality of (3) shows that the firm chooses its vacancy supply such that the value of an additional worker (i.e., $\lambda_{\mathrm{E}}$ ) is equalized to the expected recruitment costs (i.e., $\gamma / q$ ). The second equality of (3) indicates that the value of an additional

\footnotetext{
${ }^{9}$ Exogenous capital is a standard assumption in search-theoretic models.

${ }^{10}$ The assumption of a constant job break-up rate is not too unrealistic for purposes of comparative statics, but less suitable if one wants to study short-run dynamics. The present paper focuses on the former, however. See Merz (1997) and Mortensen and Pissarides (2003) for a model endogenizing the job break-up rate.
} 
worker is equal to the present discounted value of the surplus the firm earns on that job, using $r+s$ as the effective discount rate. The presence of search costs causes $\alpha>w_{\mathrm{P}}$. Equation (4) says that the value of the firm, $A_{\mathrm{P}}$, should be equal to the replacement value of its labor force.

\subsection{Households}

The representative household comprises infinitely many members caring only about the lifetime utility enjoyed by the household unit at time $t$. At a given point in time, household members engage in only one of the following activities: working, searching for a job (if unemployed), or enjoying leisure. The overall household has a fixed time endowment - which is normalized to unity for convenience-so that leisure is defined as $M \equiv 1-U-L$, where $U$ denotes units of time spent on searching for a job. Each household member supplies a fixed amount of labor time while employed, which is in line with the empirical regularity that labor supply is more responsive along the extensive margin than along the intensive margin (see Heckman 1993). The search effort of an unemployed household member is also supplied inelastically. Individual household members experience income risk in the labor market, due to idiosyncratic shocks, which is fully insured within the household. Since there are infinitely many members, household income is nonstochastic (cf. Merz 1995; Andolfatto 1996).

Lifetime utility of the representative household, denoted by $\Lambda(t)$, takes a simple logarithmic form:

$$
\Lambda(t) \equiv \int_{t}^{\infty} \log X(z) \mathrm{e}^{-r(z-t)} \mathrm{d} z,
$$

where $X$ is full consumption, which is defined as the sum of the value of goods consumption and the opportunity cost of leisure consumption. We have already imposed that the household's pure rate of time preference is equal to the rate of interest. ${ }^{11}$ Following Greenwood et al. (1988), the full consumption subutility functional is specified so as to eliminate the wealth effect in the household's labor force participation decision:

$$
X \equiv C-\frac{\sigma}{\sigma+1} L_{\mathrm{P}}^{(\sigma+1) / \sigma}, \quad \sigma \geq 0,
$$

where $C$ is private consumption, $L_{\mathrm{P}} \equiv U+L$ denotes labor force participation, and $\sigma$ is the intratemporal labor supply elasticity. Labor supply is exogenous if $\sigma=0$ and endogenous if $\sigma>0$.

At each instant of time, $f U$ unemployed household members find a job, but some employed members, $s L$, lose their job owing to idiosyncratic shocks. Then, the household's stock of employment evolves according to:

$$
\dot{L} \equiv f U-s L, \quad 0<f<1,
$$

where $f$ denotes the firm's worker-finding rate (to be determined in Sect. 2.4).

\footnotetext{
${ }^{11}$ As is well known, the representative-agent model for the small open economy only has a meaningful steady-state solution if this "knife-edge" condition is met. If the rate of interest were to exceed (fall short of) the pure rate of time preference, the economy would keep accumulating (decumulating) assets.
} 
Employed household members pay a wage tax, $\tau_{\mathrm{L}}$, that is levied on their wage income above a certain threshold $a \geq 0$, which represents the personal tax allowance. ${ }^{12}$ After-tax wage income then amounts to $\left(w_{\mathrm{N}}+\tau_{\mathrm{L}} a\right) L$, where $w_{\mathrm{N}}=w\left(1-\tau_{\mathrm{L}}\right)$ denotes the after-tax "marginal" wage and $w_{\mathrm{A}}=w_{\mathrm{N}}+\tau_{\mathrm{L}} a$ is the after-tax "average" (or consumer) wage. Unemployed workers receive a constant unemployment benefit, $b$, which is untaxed. ${ }^{13}$ The household's flow budget identity (measured in real terms) is:

$$
\dot{A} \equiv r A+\left[w_{\mathrm{N}}+\tau_{\mathrm{L}} a\right] L+b U+T-C,
$$

where $A$ is the stock of financial assets and $T$ are lump-sum transfers.

The optimization problem of the household can be solved in two stages. In the first stage, the optimal time profile of full consumption is solved by maximizing (5) subject to the household's budget constraint (8) and the relevant transversality conditions. This yields flat full consumption profiles. Hence, $X=r(A+H)$, implying that the household consumes a constant proportion of its total wealth, comprising financial wealth, $A$, and after-tax human wealth,

$$
H(t) \equiv \int_{t}^{\infty}\left[\left(w_{\mathrm{N}}(z)+\tau_{\mathrm{L}} a\right) L(z)+b U(z)-\frac{\sigma}{1+\sigma} w_{R}(z)^{1+\sigma}+T(z)\right] \mathrm{e}^{-r(z-t)} \mathrm{d} z .
$$

In the second step, full consumption is optimally allocated over its components:

$$
\begin{aligned}
U+L & =w_{\mathrm{R}}^{\sigma}, \\
w_{\mathrm{R}} & \equiv b+f \lambda_{\mathrm{L}} \\
\lambda_{\mathrm{L}}(t) & =\int_{t}^{\infty}\left[w_{\mathrm{N}}(z)+\tau_{\mathrm{L}} a-b\right] \exp \left[-\int_{t}^{z}(s+f(v)+r) \mathrm{d} v\right] \mathrm{d} z,
\end{aligned}
$$

where $w_{\mathrm{R}}$ is the worker's reservation wage and $\lambda_{\mathrm{L}}$ is the pecuniary value of an additional job. Equation (10) shows that labor market participation is a positive (nonlinear) function of the reservation wage (11), which is defined as the sum of the unemployment benefit and the expected value of a job, $f \lambda_{\mathrm{L}}$. The value of an additional job (12) is the present discounted value of the "dividend" earned on the job, consisting of the excess of net labor income over the household's outside option. ${ }^{14}$

\subsection{The government}

Lump-sum transfers to households, $T$, and outlays on unemployment benefits, $b U$, are covered by revenue from a payroll tax and a wage tax:

$$
T+b U=\left[\tau_{\mathrm{E}} w+\tau_{\mathrm{L}}(w-a)\right] L .
$$

Interest income, $r A$, is untaxed.

\footnotetext{
${ }^{12}$ In the background, we employ the linear tax function: $\Gamma \equiv \tau_{\mathrm{L}}(w-a) L$, where $a \geq 0$. If $a=0$, the tax system is proportional, otherwise, it is progressive. Note that $a$ is subtracted from the wage income of each household member rather than the wage income of the entire household. See Sect. 2.3.

${ }^{13}$ Our key results on efficiency and employment still hold if unemployment benefits were taxed.

${ }^{14}$ Assumption 1(i) (see below) guarantees that $w_{\mathrm{N}}(z)+\tau_{\mathrm{L}} a>b$.
} 
In line with general practice, wage taxes are taken to be progressive, whereas payroll taxes are assumed to be proportional. To measure the degree of tax progressiveness, we use the coefficient of average tax progression:

$$
\Psi\left(\tau_{\mathrm{E}}, \tau_{\mathrm{L}}, a\right) \equiv \tau^{\mathrm{M}}-\tau^{\mathrm{A}}=\frac{\tau_{\mathrm{L}} a}{w\left(1+\tau_{\mathrm{E}}\right)},
$$

where $\tau^{\mathrm{M}}$ denotes the marginal tax wedge and $\tau^{\mathrm{A}}$ is the average tax wedge:

$$
\tau^{\mathrm{M}} \equiv \frac{\tau_{\mathrm{L}}+\tau_{\mathrm{E}}}{1+\tau_{\mathrm{E}}}, \quad \tau^{\mathrm{A}} \equiv \tau^{\mathrm{M}}-\frac{\tau_{\mathrm{L}} a}{w_{\mathrm{P}}} .
$$

We thus define the marginal tax wedge as the difference between the wage paid by the firm and the wage received by the household expressed as a percentage of the producer wage. ${ }^{15}$ The tax system is progressive (i.e., the average tax burden rises with the wage rate) if $\Psi(\cdot)>0$, which is satisfied for $a>0$. We obtain a proportional tax system for $a=0$. An increase in one of the wage tax parameters $\left(\tau_{\mathrm{L}}\right.$ or $\left.a\right)$ at a given wage rate yields an increase in average tax progression, whereas an increase in the payroll tax reduces average tax progression ceteris paribus. Tax progression can also change owing to a change in the wage at a given tax rate, which is further analyzed in Sect. 4.

We take the design of the tax system as given. The tax-benefit system satisfies:

Assumption 1 (i) $w\left(1-\tau_{\mathrm{L}}\right)+\tau_{\mathrm{L}} a>b$; (ii) $b>a>\tau_{\mathrm{L}} a \geq 0$; and (iii) $0<$ $\tau_{\mathrm{E}}, \tau_{\mathrm{L}}<1$.

Part (i) ensures that it pays off for household members to work. Part (ii) guarantees a positive tax-adjusted unemployment benefit, that is, $b-\tau_{\mathrm{L}} a>0$. Furthermore, in keeping with OECD practice, unemployment benefits are assumed to exceed personal tax allowances, that is, $b>a$. Finally, part (iii) imposes positive initial taxes and precludes an outcome in which wage income is fully taxed away, which would leave employed households with a constant income equal to the personal tax allowance.

\subsection{Job matching}

Following Pissarides (1990), firms with vacancies and job-seeking workers are matched in a stochastic fashion. The Cobb-Douglas matching function, $Z=$ $U^{\varepsilon} V^{1-\varepsilon}, 0<\varepsilon<1$, describes the number of labor contracts, $Z$, that are concluded given the number of job seekers and vacancies. From the matching function, the job-finding rate of the worker can be derived: ${ }^{16}$

$$
f(\theta) \equiv \frac{Z}{U}=\theta^{1-\varepsilon}, \quad f^{\prime} \equiv \mathrm{d} f / \mathrm{d} \theta>0, \quad f^{\prime \prime}<0,
$$

\footnotetext{
${ }^{15}$ Defining the tax wedge with respect to the producer wage is common in the academic literature (e.g., Koskela and Schöb 1999) and policy literature (e.g., OECD 1994).

${ }^{16}$ On the one hand, $f(\theta)$ represents the fraction of individuals finding a job per unit of time. On the other hand, it represents the probability of an individual finding work. The former follows logically from the latter by the law of large numbers.
} 
where $\theta \equiv V / U$ is the relative number of traders in the market, which is an indicator of labor market tightness. It holds that $f(\theta)=\theta q(\theta)$, where $q(\theta) \equiv Z / V$ and $q^{\prime}<0<q^{\prime \prime}$. Intuitively, a tighter labor market reduces the probability for firms to fill a vacancy but makes it easier for workers to find a job. We define $0<\varepsilon \equiv-\theta q^{\prime}(\theta) / q(\theta)<1$ as the absolute value of the elasticity of the $q(\theta)$ function, so that $1-\varepsilon$ is the elasticity of the $f(\theta)$ function.

\subsection{Wage bargaining}

When a firm with a vacancy and a job-seeking worker meet, a local monopoly rent is created by the encounter, which is equal to $\lambda_{\mathrm{E}}^{i}+\lambda_{\mathrm{L}}^{i}$, where the superscript $i$ indicates a particular firm-worker pairing. Upon separation, this rent is lost. The division of the rent between the worker and the firm is determined by generalized Nash bargaining over the wage rate:

$$
w^{i}=\arg \max \left(\lambda_{\mathrm{L}}^{i}\right)^{\chi}\left(\lambda_{\mathrm{E}}^{i}\right)^{1-\chi}, \quad 0 \leq \chi \leq 1,
$$

where $\chi$ and $1-\chi$ represent the bargaining power of the worker and the firm, respectively. Because all firms are identical, they all choose the same wage.

The wage resulting from the bargaining process can be written in two equivalent ways:

$$
\begin{aligned}
w & =\chi \frac{\alpha}{1+\tau_{\mathrm{E}}}+(1-\chi) \frac{w_{\mathrm{R}}-\tau_{\mathrm{L}} a}{1-\tau_{\mathrm{L}}} \\
& =\chi \frac{\alpha+\gamma \theta}{1+\tau_{\mathrm{E}}}+(1-\chi) \frac{b-\tau_{\mathrm{L}} a}{1-\tau_{\mathrm{L}}},
\end{aligned}
$$

where (11) is used to go from the first to the second line. The negotiated wage is a weighted average of the firm's surplus - consisting of the marginal product of labor and the foregone search $\operatorname{costs}(\gamma \theta)$ adjusted for payroll and employment taxesand the tax-adjusted unemployment benefit (i.e., $\left.\left(b-\tau_{\mathrm{L}} a\right) /\left(1-\tau_{\mathrm{L}}\right)\right)$. For a given $\theta$, it follows from (18) that employers' tax rates depress wages because they reduce the surplus of the match, but also because firms and workers save on tax payments by agreeing to keep wages low. If employers have all the bargaining power, that is, $\chi=0$, the negotiated wage is independent of labor market tightness. In that case, payroll taxes do not affect wage setting. Wage taxes raise the negotiated wage as long as Assumption 1(ii) is satisfied. Intuitively, because unemployment benefits are untaxed, the outside option becomes more attractive if wages are taxed more heavily. For a given labor market tightness, the presence of a tax allowance moderates the increase in the before-tax wage. Because of increased tax progression, the benefit of a wage increase is reduced.

\section{Solving the model}

This section closes the model, presents equilibrium conditions, and develops the graphical apparatus. 


\subsection{Model closure and equilibrium}

Asset market equilibrium ensures that household wealth equals the value of outstanding assets, $A^{*}=A_{\mathrm{P}}^{*}+A_{\mathrm{F}}^{*}$, where $A_{\mathrm{F}}^{*}$ denote $n e t$ foreign assets and asterisks denote steady-state values. The evolution of net foreign assets is given by the current account balance: $\dot{A}_{\mathrm{F}}=r A_{\mathrm{F}}+[Y-\gamma V-C]$, where the term in square brackets is the trade account showing that domestic output less domestic absorption (i.e., the sum of consumption and search costs) equals net exports. To the extent that the country is a net creditor to the rest of the world ( $A_{\mathrm{F}}>0$ initially), it can afford to run current account deficits in the future. National solvency is retained provided the present value of current account deficits (the right-hand side of (19)) equals the initial level of net foreign assets (the left-hand side of (19)):

$$
A_{\mathrm{F}}(t)=-\int_{t}^{\infty}[Y(z)-\gamma V(z)-C(z)] \mathrm{e}^{r(t-z)} \mathrm{d} z .
$$

In steady state, total employment does not change $(\dot{L}=0)$, although there are still labor market flows taking place. From (7), an expression for the equilibrium unemployment rate can be obtained, that is, $u^{*}=s /\left(s+f\left(\theta^{*}\right)\right)$, where $u^{*} \equiv U^{*} / L_{\mathrm{P}}^{*}$. The model can be reduced to two equations and two unknowns (i.e., $w^{*}$ and $\theta^{*}$ ):

$$
\begin{gathered}
\alpha-w^{*}\left(1+\tau_{\mathrm{E}}\right)=(r+s) \gamma \theta^{* \varepsilon}, \\
w^{*}=\chi \frac{\alpha+\gamma \theta^{*}}{1+\tau_{\mathrm{E}}}+(1-\chi) \frac{b-\tau_{\mathrm{L}} a}{1-\tau_{\mathrm{L}}},
\end{gathered}
$$

where (20) follows from (3) and noting (16). After a shock, the model immediately returns to its steady state so that our analysis will be focused on a comparison of steady states.

\subsection{Graphical apparatus}

The model can be summarized graphically by two schedules in the $(w, \theta)$ space (Panel (a) of Fig. 1). The vacancy creation (VC) schedule (see (20)) is downward sloping and convex toward the origin, reflecting diminishing returns in vacancy creation. A lower wage rate induces firms to create more vacancies. The wage setting (WS) schedule (see (21)) is linear and upward sloping. At higher rates of labor market tightness, the worker gets a larger share of the pure rents associated with a labor contract (via a higher wage). The long-run equilibrium is represented by $E_{0}$. Panel (b) of Fig. 1 shows the Beveridge Curve (BC), which is downward sloping and convex to the origin in the $(V, U)$ space (see Blanchard and Diamond 1989). Intuitively, if there are more vacancies, unemployment is lower because unemployed household members find it easier to locate a job. The ray through the origin represents the equilibrium vacancy-unemployment ratio (i.e., the indicator of labor market tightness (LMT)). Equilibrium unemployment and vacancies are at the intersection of the LMT and BC curves. 
(a)

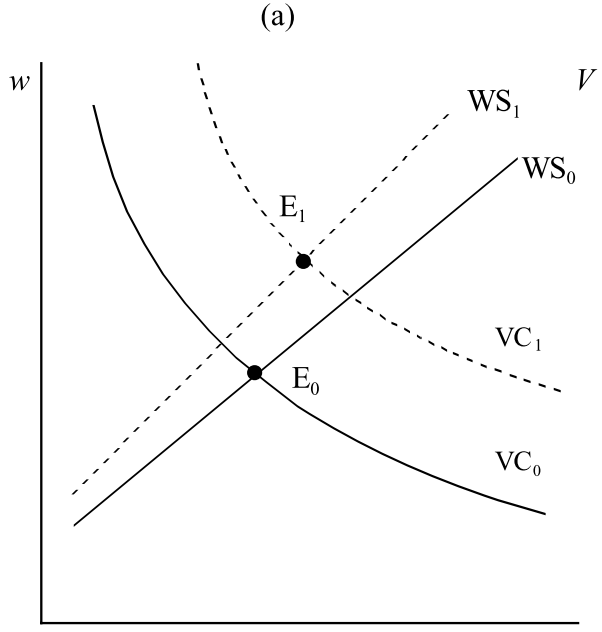

(b)

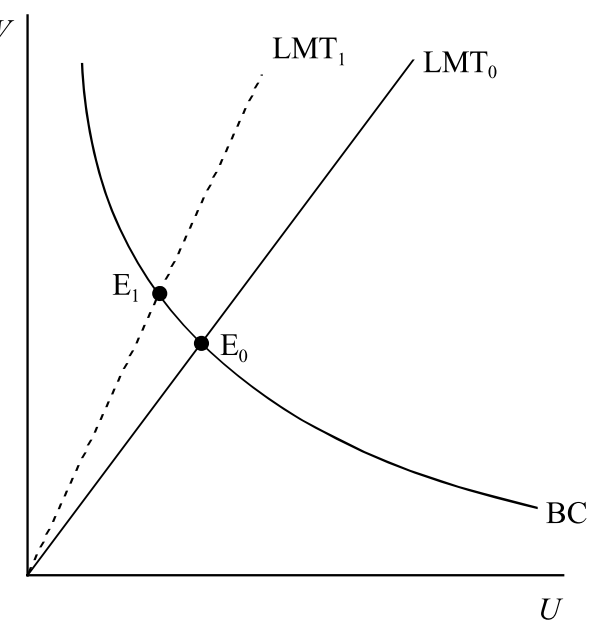

Fig. 1 Substituting wage taxes for payroll taxes

\section{Allocation effects of labor tax reform}

This section analyzes the employment and revenue effects of the labor tax reform strategy set out in the Introduction. It compares the steady state of the model before and after the policy shock. The model is log-linearized around its initial steady state, reflecting the nonlinear nature of the vacancy creation curve (Appendix A.1). Because of the local approximation, a piecemeal labor tax reform scenario is analyzed.

Consider a labor tax reform strategy which involves simultaneously cutting a payroll tax by $\mathrm{d} \tau_{\mathrm{E}}<0$ and increasing the wage tax by $\mathrm{d} \tau_{\mathrm{L}}>0$ so as to leave unaffected the marginal tax wedge (i.e., $\mathrm{d} \tau^{\mathrm{M}}=0$ ). This requires that $\mathrm{d} \tau_{\mathrm{E}}=-\phi \mathrm{d} \tau_{\mathrm{L}}$, where $\phi \equiv\left(1+\tau_{\mathrm{E}}\right) /\left(1-\tau_{\mathrm{L}}\right)>1$ denotes the coefficient of initial taxes. Because of the assumed positive initial wage and payroll taxes, the objective of keeping the marginal tax wedge constant does not yield an equi-proportionate absolute change in the wage tax rate. We assume that wages taxes are progressive (i.e., $a>0$ ). The reform then reduces the average tax wedge and increases the degree of average tax progression (see (A.7) in Appendix A.2).

In terms of Panel (a) of Fig. 1, the reform shifts up and rotates to the left the WS curve and shifts to the right the VC curve, thereby pushing up the wage rate. The new steady state $\left(E_{1}\right)$ lies to the north east of the old equilibrium $\left(E_{0}\right)$ if the wage tax is progressive. In that case, the shift in the VC curve dominates the shift in the WS curve (which can be seen from (A.2) in Appendix A.1). The reform scenario thus has desirable effects on economic efficiency; it yields a smaller search externality to job-seeking workers and a higher level of employment in the new steady state. More formally, labor market tightness changes according to:

$$
\frac{\mathrm{d} \theta^{*}}{\mathrm{~d} \tau_{\mathrm{L}}}=\frac{a \phi(1-\chi) f^{*}}{\gamma\left(\varepsilon(r+s)+\chi f^{*}\right)}>0 .
$$


The reform yields a tighter labor market if it satisfies Assumption 2. First, workers should not have all the bargaining power in wage negotiations. Second, the wage tax structure should be progressive.

Assumption 2 (i) $\chi \neq 1$; and (ii) $a>0$.

Producer wages fall-increasing the value of an additional worker to the firm-if workers' bargaining power is less than perfect. If $\chi=1$, workers could demand a wage increase large enough to fully compensate for the wage tax rise, making labor more expensive to firms than for smaller values of $\chi$. In mathematical terms, $\mathrm{d} w_{\mathrm{P}}^{*} / \mathrm{d} \tau_{\mathrm{L}}=0$ for $\chi=1$ compared with $\mathrm{d} w_{\mathrm{P}}^{*} / \mathrm{d} \tau_{\mathrm{L}}<0$ for $\chi<1$ (from (A.10) in Appendix A.2). Consumer wages rise (for $\chi>0$ ), despite the increase in the wage tax, increasing the household's labor force participation rate. ${ }^{17}$ Intuitively, the decrease in the average tax wedge, $\tau^{\mathrm{A}}$, raises the negotiated (before-tax) wage sufficiently to offset the wage tax increase. In mathematical terms, if $\chi=1$, then $\mathrm{d} w_{\mathrm{A}}^{*} / \mathrm{d} \tau_{\mathrm{L}}=a>0$ and $0<\mathrm{d} w_{\mathrm{A}}^{*} / \mathrm{d} \tau_{\mathrm{L}}<a$ for $0<\chi<1$. Note that $\mathrm{d} w_{\mathrm{A}}^{*} / \mathrm{d} \tau_{\mathrm{L}}=0$ for $\chi=0$.

The reform changes employment as follows:

$$
\frac{\mathrm{d} L^{*}}{\mathrm{~d} \tau_{\mathrm{L}}}=w_{R}^{* \sigma}\left[\sigma\left(1-u^{*}\right) \frac{\chi}{1-\chi} \frac{\gamma}{\phi w_{\mathrm{R}}^{*}}+u^{*} \frac{f^{\prime}\left(\theta^{*}\right)}{s+f^{*}}\right] \frac{\mathrm{d} \theta^{*}}{\mathrm{~d} \tau_{\mathrm{L}}}>0 .
$$

If Assumption 2 is satisfied, employment rises via two channels: (i) increased labor force participation (the first term of (23)), particularly if the labor supply elasticity is large; and (ii) a reduction in the unemployment rate (the second term of (23)), owing to firms opening up more vacancies, thereby making it easier for unemployment household members to find a job. If labor supply is exogenous (i.e., $\sigma=0$ so that the first term drops out), employment can still increase via the unemployment rate channel, but by less, due to the absence of the labor supply effect. In sum, tax progression is good for employment. But not because of the wealth effect in labor supply (i.e., households work harder to compensate for the income loss associated with the higher rate of tax progression), which is stressed in the literature (e.g., Koskela and Vilmunen 1996). In our model, tax progression benefits employment because the personal tax allowance of each household member acts as an implicit employment subsidy at the level of the household. The key efficiency result-which is summarized in Proposition 1-is extremely sharp as it is as close to practicability as one could hope for. ${ }^{18}$

Proposition 1 A cut in the payroll tax coordinated with a rise in the wage tax that keeps the marginal tax wedge unchanged strictly increases labor market tightness, the before-tax wage rate, employment, and average tax progression iff: (i) the wage

\footnotetext{
${ }^{17}$ In contrast, the revenue-neutral reform considered by Koskela and Schöb (1999) fosters employment but at the expense of workers' after-tax wages.

${ }^{18}$ Alternatively, we could have studied a revenue-neutral wage-payroll tax reform as is common in the literature. Analytically, it is less attractive, however. Under the assumption of a proportional wage tax schedule, the two tax reform strategies are identical in their economic effects.
} 
tax schedule is progressive $(a>0)$; and (ii) workers do not have all the bargaining power in wage negotiations $(\chi \neq 1)$.

Proof See Appendix A.2.

What is the effect of the reform on public revenue? Without tax base effects, a negative revenue effect would materialize. Intuitively, the tax rate on a relatively large tax base (i.e., the payroll base) is reduced while the tax rate on a relatively small base (i.e., the wage income base) is increased. ${ }^{19}$ The reform, however, increases the tax bases-via higher wages and employment - thereby more than offsetting the negative tax rate effect. If labor supply is sufficiently inelastic, aggregate unemployment falls too (see (A.13) in Appendix A.2), causing a fall in unemployment outlays. Accordingly, net lump-sum transfers, that is, gross public revenue minus unemployment outlays rise by more than gross public revenue. Proposition 2 summarizes the revenue effects.

Proposition 2 Cutting a proportional payroll tax while increasing a progressive wage tax so as to keep the marginal tax wedge constant increases public revenue.

\section{Proof See Appendix A.2.}

Propositions 1 and 2 provide for a surprisingly simple way of reaping the benefits from labor tax reform without jeopardizing the government's revenue position. If the wage tax does not provide for an initial allowance $(a=0)$, a piecemeal reallocation of the distribution of the statutory burden of payroll and wage taxes does not have an economic effect, just like in a setting of a perfectly competitive labor market. ${ }^{20}$ Revenue is not affected either because the wage tax and payroll tax bases are equal.

\section{Welfare effects of labor tax reform}

This section studies whether the reform of Sect. 4 improves welfare. We focus on the case of an infinitely lived representative household, implying that we cannot study distributional issues. Private welfare is measured by full consumption (5), which in steady state yields:

$$
\Lambda^{*}=\frac{\log X^{*}}{r}
$$

\footnotetext{
${ }^{19}$ Note that, in practice, this is not so clear-cut. Personal income taxes may include certain employment benefits (e.g., a company car) and exclude certain expenses (e.g., interest payments on a mortgage) from taxable income, whereas payroll taxes are levied upon salary with few such adjustments.

${ }^{20}$ Picard and Toulemonde $(2001,2003)$ show that a revenue-neutral restructuring of payroll and wage taxes does not affect employment if and only if both producer and consumer wages remain constant and the labor market is perfectly competitive.
} 
In view of $X^{*}=r\left(A^{*}+H^{*}\right)$, maximizing welfare is equivalent to maximizing household wealth. Substituting $\log X^{*}$ into (24) and rewriting:

$$
r \Lambda^{*}=\log r+\log \Omega^{*},
$$

where $\Omega^{*} \equiv A^{*}+H^{*}$ and $A^{*}=A_{\mathrm{P}}^{*}+A_{\mathrm{F}}^{*}$. Appendix A.3.1 expresses $\Omega^{*}$ in terms of predetermined variables.

The welfare change induced by the reform is:

$$
r \frac{\mathrm{d} \Lambda^{*}}{\mathrm{~d} \tau_{\mathrm{L}}}=\left[\sigma \Upsilon+\frac{q U^{*}}{r+s+\chi f^{*}} \Phi\right] \frac{1}{X^{*}} \frac{\mathrm{d} \theta^{*}}{\mathrm{~d} \tau_{\mathrm{L}}},
$$

where $\Upsilon, \Phi, \tau^{\mathrm{P}}$, and $\omega$ are given by (see also Appendix A.3.2):

$$
\begin{aligned}
\Upsilon & \equiv w_{\mathrm{R}}^{*(\sigma-1)} \frac{\gamma}{\phi} \frac{\chi}{1-\chi}\left[\frac{f^{*}}{r+s+f^{*}}\left(\alpha \omega \tau^{\mathrm{M}}+\left(1-\tau^{\mathrm{M}} \omega\right) \tau^{\mathrm{P}}\right)-b\right], \\
\Phi & \equiv(\chi-\varepsilon) \alpha+\tau^{\mathrm{P}}(1-\chi) \frac{r+s+\varepsilon f^{*}}{r+s+f^{*}}, \\
\tau^{\mathrm{P}} & \equiv\left(1+\tau_{\mathrm{E}}\right) \frac{b-\tau_{\mathrm{L}} a}{1-\tau_{\mathrm{L}}}>0, \\
0<\omega & \equiv \chi \frac{r+s+f^{*}}{r+s+\chi f^{*}}<1 .
\end{aligned}
$$

Introducing a wage tax in a first-best world - in which initial labor taxes and unemployment benefits are zero (and thus relaxing Assumptions 1 and 2(ii)) - does not yield a first-order welfare effect if the Hosios (1990) condition is met. In formal terms, $\tau^{\mathrm{P}}=0, \Upsilon=0$, and $\Phi=(\chi-\varepsilon) \alpha=0$ (from (26)). The Hosios condition, $\chi=\varepsilon$, says that workers' bargaining power $(\chi)$ should equal unemployed workers' effectiveness in finding a job $(\varepsilon)$. In that case, all search externalities that characterize the market outcome are fully internalized. Intuitively, at the margin, the creation of an additional vacancy creates two externalities. One externality is positive because it becomes easier for job-seeking workers to find a job. The other externality is negative, reflecting the congestion the vacancy-opening firm is imposing on other firms that are seeking workers. Under the Hosios condition, the two externalities offset each other. If the bargaining power of workers exceeds its socially efficient level (i.e., $\chi>\varepsilon$ ), vacancy-creating firms will be under-compensated for their efforts to post vacancies, yielding a deficient number of vacancies. Conversely, if workers' bargaining power falls short of its socially efficient level (i.e., $\chi<\varepsilon$ ), the number of vacancies posted by firms is excessive. Because the matching technology is Cobb-Douglas, $\varepsilon$ is a constant taking on values between zero and unity. In addition, $\chi$ is given on the $[0,1]$ interval. Because of the constancy of these two parameters, the Hosios condition can be satisfied by accident only. If the conditions set out in Lemma 1 are satisfied, the market outcome coincides with the socially efficient solution.

Lemma 1 The market solution is efficient if the following two conditions hold: (i) $\tau_{\mathrm{E}}=\tau_{\mathrm{L}}=a=b=0$; and (ii) $\chi=\varepsilon$. 
Lemma 1(i) is generally (and also in our case) not satisfied, so that we end up in a second-best world, which features preexisting labor taxes and unemployment benefits. We assume $\tau_{\mathrm{E}}, \tau_{\mathrm{L}}, a, b>0$. Define $\chi_{0}^{\mathrm{F}}$ and $\chi_{0}^{\mathrm{S}}$ as the bargaining power of workers required to yield a zero welfare change (denoted by " 0 ") in a first-best world (labeled by superscript F) and a second-best world (labeled S), respectively. If labor supply is exogenous, the first term of (26) drops out. In that case, $\chi^{\mathrm{S}} \geq \chi_{0}^{\mathrm{F}} \equiv \varepsilon$ is a sufficient condition (and $\chi^{\mathrm{S}}>\chi_{0}^{\mathrm{S}}$ is a necessary condition) to yield an increase in welfare (see (27)). Intuitively, progressive labor taxes reduce the effective bargaining power of workers and take the market outcome closer to the first-best optimal value. ${ }^{21}$ The smaller wage claim of workers raises employment and output, reduces unemployment, and diminishes unemployment outlays. Welfare thus rises if average tax progression rises. More formally, by setting $\chi^{\mathrm{S}}=\varepsilon$ in the expression for $\Phi=0$, we can see that $\Phi>0$ (reflecting Assumptions 1(ii)-(iii), which prescribe $\left.b-\tau_{\mathrm{L}} a>0\right){ }^{22}$ The argument can be seen more clearly by deriving the optimal second-best $\chi$, which we call the modified Hosios condition. By setting $\Phi=0$, we find:

$$
\chi_{0}^{\mathrm{S}} \equiv \frac{\alpha \varepsilon\left(r+s+f^{*}\right)-\tau^{\mathrm{P}}\left(r+s+f^{*} \varepsilon\right)}{\alpha\left(r+s+f^{*}\right)-\tau^{\mathrm{P}}\left(r+s+f^{*} \varepsilon\right)}<\chi_{0}^{\mathrm{F}} \equiv \varepsilon .
$$

In contrast to the first-best $\chi$, the second-best $\chi$ is a function of tax policy variables and labor market tightness. We can derive:

$$
\frac{\partial \chi_{0}^{\mathrm{S}}}{\partial \tau^{\mathrm{P}}}=-\frac{\alpha(1-\varepsilon)\left(r+s+f^{*}\right)\left(r+s+f^{*} \varepsilon\right)}{\left[(r+s)\left(\alpha-\tau^{\mathrm{P}}\right)+f^{*}\left(\alpha-\varepsilon \tau^{\mathrm{P}}\right)\right]^{2}}<0,
$$

with derivatives:

$$
\frac{\partial \tau^{\mathrm{P}}}{\partial \tau_{\mathrm{L}}}<0, \quad \frac{\partial \tau^{\mathrm{P}}}{\partial \tau_{\mathrm{E}}}>0, \quad \frac{\partial \tau^{\mathrm{P}}}{\partial a}<0, \quad \frac{\partial \tau^{\mathrm{P}}}{\partial b}>0 .
$$

It can be seen that a more progressive tax system (a larger value of $a$ and thus a smaller $\tau^{\mathrm{P}}$ ) takes the second-best market outcome closer to the first best. A larger unemployment benefit (a larger $b$ ) raises $\tau^{\mathrm{P}}$ and thus reduces the required bargaining power of workers. If labor supply is endogenous, initial unemployment benefits have an ambiguous effect on welfare (see (A.30) in Appendix A.3.2). If initial unemployment benefits are not too large and labor supply is not too elastic, the reform raises welfare. ${ }^{23}$ Proposition 3 summarizes the results.

Proposition 3 Substituting a progressive wage tax for a linear payroll tax yields an increase in welfare if workers have a sufficient amount of bargaining power. If labor

\footnotetext{
${ }^{21}$ This point is also made, but in a different context, by Boone and Bovenberg (2002).

${ }^{22}$ Assumption 1(ii) plays a key role in our welfare analysis. Note that for $b=\tau_{\mathrm{L}} a$, in which case Assumption 1(ii) is breached, we find $\Phi=(\chi-\varepsilon) \alpha$. Hence, no welfare gain is realized if the first-best Hosios condition is met.

${ }^{23}$ The positive welfare effect disappears if three conditions are met: (i) either $\Upsilon=0$ or $\sigma=0$; (ii) $\tau^{\mathrm{P}}=0$ (if $b=\tau_{\mathrm{L}} a$ ); and (iii) $\chi=\varepsilon$.
} 
supply is exogenous, then $\chi^{\mathrm{S}} \geq \chi_{0}^{\mathrm{F}} \equiv \varepsilon$ is a sufficient condition and $\chi^{\mathrm{S}}>\chi_{0}^{\mathrm{S}}$ is a necessary condition to yield a welfare improvement.

Proof See Appendix A.3.2.

\section{Conclusions}

Many European countries face high equilibrium unemployment rates at a time when their public finances are already overstretched. Policy makers have, therefore, shifted away their attention from resource-consuming public subsidies to resourceconserving reforms of the labor tax structure as ways to address the unemployment problem. The formal theory on labor tax reform offers surprisingly little guidance on what kind of reform policy makers should embark on to reduce equilibrium unemployment without putting the government's revenue position at risk. In this context, the paper has embedded a search and matching model of the labor market in a small open economy model, featuring endogenous labor supply, progressive wage taxes, and payroll taxes. With the aid of the model, we study a simple and practical labor tax reform strategy.

It is shown that a strategy of cutting a proportional payroll tax and increasing a progressive wage tax so as to keep the marginal tax wedge constant, yields a "double dividend" if workers have less than complete bargaining power. It reduces the equilibrium unemployment rate and increases public revenue. Employment rises because of the implicit employment subsidy provided by the progressive nature of the wage tax. Welfare increases if workers have a sufficient amount of bargaining power. If labor supply is exogenous, a sufficient condition to yield a welfare improvement is that workers' bargaining power is greater than or equal to the optimal value of workers' bargaining power in a first-best world (as determined by the Hosios condition). The accompanying necessary condition, however, prescribes that the degree of workers' bargaining power should exceed its optimal second-best value, which is smaller than its first-best value. Note that the optimal second-best value of workers' bargaining depends negatively on unemployment benefits and positively on the tax exempt threshold. If labor is endogenous, unemployment benefits have an ambiguous effect on the second-best Hosios condition. If initial unemployment benefits are not too large and labor supply is not too elastic, welfare rises. The reform, however, does not affect employment, public revenue, and welfare if the wage tax is proportional.

Our analysis has abstracted, it should be emphasized, from physical capital so that the income tax applies to labor income only. Allowing for physical capital would broaden the income tax base. Because of such differences in the income tax base, a shift from payroll taxes to income taxation would involve an increase in the overall effective tax burden on capital, thereby favoring labor-intensive production methods. In that case, a shift in the composition of the tax wedge would have real effects even if the wage tax is proportional. Further limitations of the analysis stem from ignoring tax compliance and tax administration issues. Social security contributions are withheld at source and are, therefore, more difficult to evade than self-assessed personal income taxes. A shift from payroll taxes to personal income taxes may then possibly 
reinforce the positive employment effects. Finally, we need to investigate how the equivalence result is affected if unemployment benefits were indexed to wages. ${ }^{24}$

Acknowledgements We thank Alex Cukierman, Emmanuel Saez, Jean-François Tremblay, Jay Wilson, and two anonymous referees for helpful comments.

\section{Appendix}

This Appendix presents the formal analysis underlying the results described in the main text. First, it analyzes the comparative statics of the labor tax reform scenario. Second, the welfare effects of the reform are studied.

\section{A.1 Log-linearized system}

The vacancy creation curve (20) is nonlinear, and, therefore, the system (20-21) is log-linearized around the initial steady state (denoted by SS). A relative change of a variable is denoted by a tilde ( ), for example, $\tilde{\theta} \equiv \mathrm{d} \theta / \theta$, except for $\tilde{\tau}_{\mathrm{E}} \equiv \mathrm{d} \tau_{\mathrm{E}} /\left(1+\tau_{\mathrm{E}}\right)$ and $\tilde{\tau}_{\mathrm{L}} \equiv \mathrm{d} \tau_{\mathrm{L}} /\left(1-\tau_{\mathrm{L}}\right)$. For convenience, we have dropped the asterisks to denote steady-state values. This yields the following system of equations:

$$
\left[\begin{array}{cc}
\frac{\varepsilon \gamma(r+s)}{q} & \left(1+\tau_{\mathrm{E}}\right) w \\
\chi \gamma \theta & -\left(1+\tau_{\mathrm{E}}\right) w
\end{array}\right]_{\mathrm{SS}}\left[\begin{array}{c}
\tilde{\theta} \\
\tilde{w}
\end{array}\right]=\left[\begin{array}{c}
\delta_{\theta} \\
\delta_{w}
\end{array}\right]
$$

where the change in the policy variables is given by:

$$
\left[\begin{array}{l}
\delta_{\theta} \\
\delta_{\mathrm{w}}
\end{array}\right] \equiv\left[\begin{array}{c}
0 \\
-(1-\chi) \phi(b-a)
\end{array}\right] \tilde{\tau}_{\mathrm{L}}+\left[\begin{array}{c}
-w\left(1+\tau_{\mathrm{E}}\right) \\
w\left(1+\tau_{\mathrm{E}}\right)-(1-\chi) \phi\left(b-\tau_{\mathrm{L}} a\right)
\end{array}\right] \tilde{\tau}_{\mathrm{E}} .
$$

By using Cramer's rule, we can solve the model for $\tilde{\theta}$ and $\tilde{w}$, which in turn determine equilibrium unemployment and vacancies. In deriving the expressions below, we impose Assumption 1. In addition, the personal tax allowance is strictly positive (see Assumption 2(ii)).

\section{A.2 Allocation and revenue effects}

Perturbing the marginal tax wedge, $\tau^{\mathrm{M}}$ (see (15)), gives:

$$
\mathrm{d} \tau^{\mathrm{M}}=\frac{\partial \tau^{\mathrm{M}}}{\partial \tau_{\mathrm{E}}} \mathrm{d} \tau_{\mathrm{E}}+\frac{\partial \tau^{\mathrm{M}}}{\partial \tau_{\mathrm{L}}} \mathrm{d} \tau_{\mathrm{L}}
$$

By setting $\mathrm{d} \tau^{\mathrm{M}}=0,(\mathrm{~A} .3)$ reduces to

$$
\phi \mathrm{d} \tau_{\mathrm{L}}=-\mathrm{d} \tau_{\mathrm{E}}>0
$$

where $\mathrm{d} \tau_{\mathrm{E}}<0$ and $\phi \equiv\left(1+\tau_{\mathrm{E}}\right) /\left(1-\tau_{\mathrm{L}}\right)>1$. Alternatively, (A.4) can be written as $\tilde{\tau}_{\mathrm{L}}=-\tilde{\tau}_{\mathrm{E}}>0$.

\footnotetext{
${ }^{24}$ See Mortensen and Pissarides (2003) for a model that links unemployment benefits to average wages.
} 
Wages and labor market tightness By substituting (A.4) into the linearized system of equations (A.1-A.2), we find:

$$
\begin{gathered}
\frac{\mathrm{d} \theta}{\mathrm{d} \tau_{\mathrm{L}}}=\frac{a \phi(1-\chi) f}{\gamma(\varepsilon(r+s)+\chi f)}>0, \\
\frac{\mathrm{d} w}{\mathrm{~d} \tau_{\mathrm{L}}}=\frac{\chi(\alpha+\gamma \theta)}{\left(1+\tau_{\mathrm{E}}\right)\left(1-\tau_{\mathrm{L}}\right)}+\frac{(1-\chi)\left[\chi f\left(b-\tau_{\mathrm{L}} a\right)+\varepsilon(r+s)(b-a)\right]}{\left(1-\tau_{\mathrm{L}}\right)^{2}(\varepsilon(r+s)+\chi f)}>0, \text { (A.6) }
\end{gathered}
$$

where use is made of (18) in going from the first line to the second line of (A.6). Equation (A.5) shows that labor market tightness rises as long as Assumption 2 holds. Because of Assumption 1(ii) the second term of (A.6) is positive.

Perturbing (14) shows the increase in average tax progression:

$$
\frac{\mathrm{d} \Psi}{\mathrm{d} \tau_{\mathrm{L}}}=\frac{a}{w_{\mathrm{P}}}\left[1-\frac{\tau_{\mathrm{L}}}{1-\tau_{\mathrm{L}}} \epsilon_{\tau_{\mathrm{L}}}^{\mathrm{P}}\right]>0,
$$

where the elasticity of the producer wage to the tax change is:

$$
\epsilon_{\tau_{\mathrm{L}}}^{\mathrm{P}} \equiv \frac{\mathrm{d} w_{\mathrm{P}}}{\mathrm{d} \tau_{\mathrm{L}}} \cdot \frac{1-\tau_{\mathrm{L}}}{w_{\mathrm{P}}}=-\frac{\varepsilon(r+s)(1-\chi)(a / w)}{\varepsilon(r+s)+\chi f}<0 .
$$

This implies that $\Psi^{\prime}(\cdot)>0$. The consumer wage and producer wage change as follows:

$$
\begin{aligned}
\frac{\mathrm{d} w_{\mathrm{A}}}{\mathrm{d} \tau_{\mathrm{L}}} & =\frac{\chi[\varepsilon(r+s)+f] a}{\varepsilon(r+s)+\chi f}>0, \\
\frac{\mathrm{d} w_{\mathrm{P}}}{\mathrm{d} \tau_{\mathrm{L}}} & =-\frac{\varepsilon(r+s)(1-\chi)\left(1+\tau_{\mathrm{E}}\right) a}{[\varepsilon(r+s)+\chi f]\left(1-\tau_{\mathrm{L}}\right)}<0,
\end{aligned}
$$

so that the consumer wage increases and the producer wage falls.

Employment and unemployment Differentiating the expression for the steady-state unemployment rate, $u=s /(s+f$ ) (from (7) for $\dot{L}=0$ ), yields the change in the unemployment rate:

$$
\frac{\mathrm{d} u}{\mathrm{~d} \tau_{\mathrm{L}}}=-u \frac{f^{\prime}(\theta)}{s+f} \frac{\mathrm{d} \theta}{\mathrm{d} \tau_{\mathrm{L}}}<0, \quad f^{\prime}(\theta)>0,
$$

where the unemployment rate is defined in the usual fashion as the proportion of job seekers in the labor force, that is, $u \equiv U / L_{\mathrm{P}}$. The change in employment follows from differentiating $L=(1-u) w_{\mathrm{R}}^{\sigma}$. The latter is derived by substituting $U=w_{\mathrm{R}}^{\sigma}-L$ (from (10)) into $L=(f / s) U$ (from (7)) to arrive at:

$$
\frac{\mathrm{d} L}{\mathrm{~d} \tau_{\mathrm{L}}}=w_{\mathrm{R}}^{\sigma}\left[\sigma(1-u) \frac{\chi}{1-\chi} \frac{\gamma}{\phi w_{\mathrm{R}}}+u \frac{f^{\prime}}{s+f}\right] \frac{\mathrm{d} \theta}{\mathrm{d} \tau_{\mathrm{L}}}>0 .
$$


If labor supply is exogenous (i.e., $\sigma=0$ ), the first term drops out. In this case, $U+L=1$, so that $\mathrm{d} u=\mathrm{d} U=-\mathrm{d} L$. If labor supply is endogenous, we find in a similar fashion:

$$
\frac{\mathrm{d} U}{\mathrm{~d} \tau_{\mathrm{L}}}=w_{\mathrm{R}}^{\sigma} u\left[\sigma \frac{\chi}{1-\chi} \frac{\gamma}{\phi w_{\mathrm{R}}}-\frac{f^{\prime}}{s+f}\right] \frac{\mathrm{d} \theta}{\mathrm{d} \tau_{\mathrm{L}}} \gtrless 0 .
$$

Unemployment is sure to fall if: (i) the labor supply elasticity is zero; (ii) firms have all the bargaining power; or (iii) search costs are zero.

Public revenue The relative change in public revenue is given by:

$$
\begin{aligned}
\frac{\mathrm{d} R}{\mathrm{~d} \tau_{\mathrm{L}}}= & -\left[\frac{\tau_{\mathrm{E}}+\tau_{\mathrm{L}}-(a / w)\left(1-\tau_{\mathrm{L}}\right)}{1-\tau_{\mathrm{L}}}\right] w L+\left(\tau_{\mathrm{E}}+\tau_{\mathrm{L}}\right) L \frac{\mathrm{d} w}{\mathrm{~d} \tau_{\mathrm{L}}} \\
& +\left[\tau_{\mathrm{E}} w+(w-a) \tau_{\mathrm{L}}\right] \frac{\mathrm{d} L}{\mathrm{~d} \tau_{\mathrm{L}}},
\end{aligned}
$$

which follows from linearizing the right-hand side of (13). Substituting (A.6) into (A.14) shows that public revenue unambiguously rises if employment expands:

$$
\begin{aligned}
\frac{\mathrm{d} R}{\mathrm{~d} \tau_{\mathrm{L}}}= & \frac{\varepsilon(r+s)\left[1-\tau_{\mathrm{L}}-(1-\chi)\left(\tau_{\mathrm{E}}+\tau_{\mathrm{L}}\right)\right]+\chi f\left(1-\tau_{\mathrm{L}}\right)}{[\varepsilon(r+s)+\chi f]\left(1-\tau_{\mathrm{L}}\right)} a L \\
& +\left[\tau_{\mathrm{E}} w+(w-a) \tau_{\mathrm{L}}\right] \frac{\mathrm{d} L}{\mathrm{~d} \tau_{\mathrm{L}}}>0,
\end{aligned}
$$

where $\varepsilon(r+s)\left[1-\tau_{\mathrm{L}}-(1-\chi)\left(\tau_{\mathrm{E}}+\tau_{\mathrm{L}}\right)\right]+f \chi\left(1-\tau_{\mathrm{L}}\right)>0$ for reasonable parameter values, implying that the first term of (A.15) is positive. If all taxes are proportional, the first and second term are zero.

\section{A.3 Welfare effects}

\section{A.3.1 Deriving the welfare function}

Lifetime utility is given by:

$$
\begin{aligned}
\Lambda(t) & \equiv \int_{t}^{\infty} \log X(z) \mathrm{e}^{-r(z-t)} \mathrm{d} z \Rightarrow \\
& =\frac{\log X}{r} \Rightarrow r \Lambda=\log r+\log [A+H] .
\end{aligned}
$$

Equation (A.16) says that maximizing welfare is equivalent to maximizing total wealth, which is defined as $\Omega \equiv A+H$, where $H$ is defined in (9). Total wealth can be rewritten by using (2), (9), and (11):

$$
\Omega=A_{\mathrm{F}}+\int_{t}^{\infty}\left[\alpha L(z)-\gamma V(z)-\frac{\sigma}{1+\sigma} w_{\mathrm{R}}^{1+\sigma}\right] \mathrm{e}^{-r(z-t)} \mathrm{d} z,
$$


where it should be borne in mind that variables like $f(\theta)$ and $w_{\mathrm{R}}$ are at their steadystate values. The term in square brackets on the right-hand side of (A.17) can be rewritten as:

$$
[\cdot]=(\alpha+\gamma \theta) L-\gamma \theta w_{\mathrm{R}}^{\sigma}-\frac{\sigma}{1+\sigma} w_{\mathrm{R}}^{1+\sigma} .
$$

By using (7), we can write $\dot{L}+(s+f) L=f w_{\mathrm{R}}^{\sigma}$. Solving this first-order differential equation yields:

$$
L(z)=\left[1-\mathrm{e}^{-(s+f)(z-t)}\right] \frac{f}{s+f} w_{\mathrm{R}}^{\sigma}+\mathrm{e}^{-(s+f)(z-t)} L,
$$

where $L$ is the initial stock of employment. By using (A.18) and (A.19), we can rewrite (A.17) as:

$$
\begin{aligned}
\Omega & =A_{\mathrm{F}}+\frac{1}{r}\left[\frac{\alpha+\gamma \theta}{r+s+f}\left(f w_{\mathrm{R}}^{\sigma}+r L\right)-\gamma \theta w_{\mathrm{R}}^{\sigma}-\frac{\sigma}{1+\sigma} w_{\mathrm{R}}^{1+\sigma}\right], \\
w_{\mathrm{R}} & \equiv b+\frac{\chi}{1-\chi} \frac{\gamma \theta}{\phi} .
\end{aligned}
$$

Equation (A.20) expresses $\Omega$ in terms of the predetermined variables (i.e., $A_{\mathrm{F}}$ and $L$ ) and labor market tightness $(\theta)$ for given values of the policy variables.

\section{A.3.2 Comparative statics}

Exogenous labor supply If labor supply is exogenous (i.e., $\sigma=0$ ), (A.20) reduces to:

$$
\Omega=A_{\mathrm{F}}+\frac{1}{r}\left[\frac{\alpha+\gamma \theta}{r+s+f}(f+r L)-\gamma \theta\right] .
$$

By differentiating (A.22) with respect to $\theta$, we obtain:

$$
\begin{aligned}
r \frac{\mathrm{d} \Omega}{\mathrm{d} \theta} & =1-\frac{f+r L}{r+s+f}\left[\frac{\alpha+\gamma \theta}{r+s+f} \frac{\mathrm{d} f}{\mathrm{~d} \theta}-\gamma\right] \\
& =\frac{s}{s+f} \frac{q}{r+s+f}\left[(\alpha+\gamma \theta)(1-\varepsilon)-\frac{\gamma}{q}(r+s+f)\right],
\end{aligned}
$$

where $1-\varepsilon \equiv \theta f^{\prime}(\theta) / f(\theta)$ and $f(\theta) \equiv \theta q(\theta)$ are used. The term in square brackets on the right-hand side of (A.23) is simplified as follows:

$$
\begin{aligned}
{[\cdot] } & =\alpha(1-\varepsilon)-\frac{\gamma}{q}(r+s+\varepsilon f) \\
& =\alpha(\chi-\varepsilon) \frac{r+s+f}{r+s+\chi f}+\tau^{\mathrm{P}}(1-\chi) \frac{r+s+\varepsilon f}{r+s+\chi f},
\end{aligned}
$$

where the composite preexisting tax rate, $\tau^{\mathrm{P}}$, is given by:

$$
\tau^{\mathrm{P}} \equiv\left(1+\tau_{\mathrm{E}}\right) \frac{b-\tau_{\mathrm{L}} a}{1-\tau_{\mathrm{L}}}>0,
$$


where we have used $\lambda_{\mathrm{E}}=\gamma / q=(1-\chi)\left(\alpha-\phi\left(b-\tau_{\mathrm{L}} a\right)\right) /(r+s+f)$ (from (3) and (18)) to eliminate $\gamma / q$ in going from the first to the second line of (A.24). By substituting (A.24) into (A.23), and noting that $\mathrm{d} \Lambda / \mathrm{d} \tau_{\mathrm{L}}=(1 / X)(\mathrm{d} \Omega / \mathrm{d} \theta)\left(\mathrm{d} \theta / \mathrm{d} \tau_{\mathrm{L}}\right)$, we arrive at:

$$
r \frac{\mathrm{d} \Lambda}{\mathrm{d} \tau_{\mathrm{L}}}=\left[(\chi-\varepsilon) \alpha+\tau^{\mathrm{P}}(1-\chi) \frac{r+s+\varepsilon f}{r+s+f}\right] \frac{1}{X} \frac{q U}{r+s+\chi f} \frac{\mathrm{d} \theta}{\mathrm{d} \tau_{\mathrm{L}}} .
$$

Defining:

$$
\Phi \equiv(\chi-\varepsilon) \alpha+\tau^{\mathrm{P}}(1-\chi) \frac{r+s+\varepsilon f}{r+s+f} .
$$

Setting $\Phi=0$ yields the second-best Hosios condition:

$$
\chi_{0}^{\mathrm{S}} \equiv \frac{\alpha \varepsilon(r+s+f)-\tau^{\mathrm{P}}(r+s+f \varepsilon)}{\alpha(r+s+f)-\tau^{\mathrm{P}}(r+s+f \varepsilon)} .
$$

Defining $\Xi \equiv \chi_{0}^{\mathrm{S}}-\chi_{0}^{\mathrm{F}}$ gives rise to:

$$
\Xi=-\frac{(1-\varepsilon)(r+s+f \varepsilon) \tau^{\mathrm{P}}}{(r+s)\left(\alpha-\tau^{\mathrm{P}}\right)+f\left(\alpha-\varepsilon \tau^{\mathrm{P}}\right)}<0,
$$

implying that $\chi_{0}^{\mathrm{S}}<\chi_{0}^{\mathrm{F}} \equiv \varepsilon$.

Endogenous labor supply In this case, represented by $\sigma>0$, we need to recognize the endogeneity of the reservation wage, $w_{\mathrm{R}}$. By differentiating (A.20) with respect to $\theta$ and simplifying, we obtain:

$$
r \frac{\mathrm{d} \Omega}{\mathrm{d} \theta}=\sigma \Upsilon+\frac{q U}{r+s+\chi f} \Phi
$$

where we have made use of $L=f w_{\mathrm{R}}^{\sigma} /(s+f), U=s w_{\mathrm{R}}^{\sigma} /(s+f)$ and (A.21) in deriving (A.30). Thus, we arrive at (26). The parameter $\Upsilon$ is also defined in (26), which can be rewritten:

$$
\Upsilon \equiv w_{\mathrm{R}}^{\sigma-1} \frac{\gamma}{\phi} \frac{\chi}{1-\chi} \frac{f}{r+s+f} \Theta
$$

where $\Theta$ is defined as

$$
\Theta \equiv \frac{\alpha f \chi \tau^{\mathrm{M}}}{r+s+\chi f}-a \Theta_{\mathrm{A}}-b \Theta_{\mathrm{B}},
$$

where $\Theta_{\mathrm{A}}$ and $\Theta_{\mathrm{B}}$ are defined as:

$$
\begin{aligned}
& \Theta_{\mathrm{A}} \equiv \frac{\tau_{\mathrm{L}} \phi f}{r+s+f}\left[1-\frac{r+s+f}{r+s+\chi f} \chi \tau^{\mathrm{M}}\right]>0, \\
& \Theta_{\mathrm{B}} \equiv \frac{(r+s)\left[\left(1-\tau_{\mathrm{L}}\right)(r+s)+\chi f\left(1+\tau_{\mathrm{E}}\right)-f\left(\tau_{\mathrm{E}}+\tau_{\mathrm{L}}\right)\right]}{(r+s+f)(r+s+\chi f)\left(1-\tau_{\mathrm{L}}\right)} .
\end{aligned}
$$


Open Access This article is distributed under the terms of the Creative Commons Attribution Noncommercial License which permits any noncommercial use, distribution, and reproduction in any medium, provided the original author(s) and source are credited.

\section{References}

Andolfatto, D. (1996). Business cycles and labor market search. American Economic Review, 86, 112132.

Blanchard, O., \& Diamond, P. (1989). The beveridge curve. Brookings Papers on Economic Activity, 1, $1-60$.

Boone, J., \& Bovenberg, A. L. (2002). Optimal labor taxation and search. Journal of Public Economics, 85, 53-97.

Dalton, H. (1954). Principles of public finance. London: Routledge and Kegan.

Greenwood, J., Hercowitz, Z., \& Huffman, G. W. (1988). Investment, capacity utilization, and the real business cycle. American Economic Review, 78, 402-417.

Hamermesh, D. S. (1993). Labor demand. Princeton: Princeton University Press.

Hansen, C. T. (1999). Lower tax progression, longer hours, and higher wages. Scandinavian Journal of Economics, 101, 49-65.

Heckman, J. J. (1993). What has been learned about labor supply in the past twenty years? American Economic Review, 83, 116-121.

Heijdra, B. J., \& Ligthart, J. E. (2002). The hiring subsidy Cum firing tax in a search model of unemployment. Economics Letters, 75, 97-108.

Heijdra, B. J., \& Van der Ploeg, F. (2002). Foundations of modern macroeconomics. Oxford: Oxford University Press.

Holm, P., Honkapohja, S., \& Koskela, E. (1994). A monopoly union model of wage determination with capital and taxes: an empirical application to Finnish manufacturing. European Economic Review, 38, 285-303.

Hosios, A. J. (1990). On the efficiency of matching and related models of search and unemployment. Review of Economic Studies, 57, 279-298.

Koskela, E., \& Schöb, R. (1999). Does the composition of wage and payroll taxes matter under Nash bargaining?. Economics Letters, 64, 343-349.

Koskela, E., \& Vilmunen, J. (1996). Tax progression is good for employment in popular models of trade union behavior. Labour Economics, 3, 65-80.

Leibfritz, W., Thorton, J., \& Bibbee, A. (1997). Taxation and economic performance (Economics Department Working Papers 176). OECD, Paris.

Lockwood, B., \& Manning, A. (1993). Wage setting and the tax system. Journal of Public Economics, 52, 1-29.

Merz, M. (1995). Search in the labor market and the real business cycle. Journal of Monetary Economics, $36,269-872$.

Merz, M. (1997). A market structure for an environment with heterogeneous job-matches, indivisible labour and persistent unemployment. Journal of Economic Dynamics and Control, 21, 853-872.

Mortensen, D. T., \& Pissarides, C. (2003). Taxes, subsidies, and equilibrium labour market outcomes. In E. S. Phelps (Ed.), Designing inclusion: tools to raise low-end pay and employment in private enterprise. Cambridge: Cambridge University Press.

Musgrave, R. A., \& Musgrave, P. B. (1987). Public finance in theory and practice (4th ed.). New York: McGraw-Hill.

OECD (1994). The OECD jobs study: evidence and explanation. Paris: OECD.

Picard, P. M., \& Toulemonde, E. (2001). On the equivalence of taxes paid by employers and employees. Scottish Journal of Political Economy, 48, 461-470.

Picard, P. M., \& Toulemonde, E. (2003). Taxation and labor markets. Journal of Economics, 78, $29-56$.

Pissarides, C. A. (1990). Equilibrium unemployment theory (1st ed.). Oxford: Basil Blackwell.

Pissarides, C. A. (1998). The impact of employment tax cuts on unemployment and wages: the role of unemployment benefits and tax structure. European Economic Review, 42, 155-183.

Pissarides, C. A. (2000). Equilibrium unemployment theory (2nd ed.). Oxford: Basil Blackwell.

Riedl, A., \& Tyran, J.-R. (2005). Tax liability side equivalence in gift-exchange labor markets. Journal of Public Economics, 89, 2369-2382. 
Rogerson, R., Shimer, S., \& Wright, R. (2005). Search-theoretic models of the labor market: a survey. Journal of Economic Literature, XLIII, 959-988.

Shapiro, J. (2004). Wage inequality in a frictional labor market. Journal of Public Economics, 88, 465579.

Shi, S., \& Wen, Q. (1999). Labor market search and dynamic effects of taxes and subsidies. Journal of Monetary Economics, 43, 457-495.

Summers, L. H. (1989). Some simple economics of mandated benefits. American Economics Review, 79, 177-183.

Symons, J., \& Robertson, D. (1990). Employer versus employee taxation: the impact on employment. In OECD employment outlook. Paris: OECD. 